\title{
O desenvolvimento da identidade docente por professores de Computação não licenciados atuantes na Educação Profissional de Nível Médio
}

\author{
Ranansamir Sousa da Silva'; Ecivaldo de Souza Matos ${ }^{1}$; Monica de Sousa Massa ${ }^{2}$ \\ ${ }^{1}$ Departamento de Ciência da Computação - Universidade Federal da Bahia (UFBA) \\ Salvador - BA - Brasil \\ ${ }^{2}$ Departamento de C. Exatas e da Terra - Universidade do Estado da Bahia (UNEB) \\ Salvador - BA - Brasil \\ \{ranansamir.silva; ecivaldo\}@ufba.br, monicamassa@gmail.com
}

\begin{abstract}
Teacher identity is a process, whose social and professional dimensions are interrelated, being strongly affected by the school context. This paper presents results of an investigation about the development process of the teaching identity by Computing professionals with no pedagogical training in undergraduate course, but that act as teachers of Professional Education at a public school in the state of Bahia. The data were collected by interviews and participant observation of Computing classes during a school year. The data analysis revealed some aspects about the difficult to establish teaching identity by those subjects, and that difficulty may influence the success of their didactic action.
\end{abstract}

Resumo. A identidade docente é um processo de construção, cujas dimensões social e profissional estão inter-relacionadas, sendo fortemente afetado pelo contexto escolar. Este artigo apresenta resultados de uma investigação qualitativa sobre o processo de desenvolvimento da identidade docente por profissionais de Computação sem formação pedagógica em nível de Licenciatura, atuantes como professores da Educação Profissional de Nível Médio em uma escola pública do estado da Bahia. Os dados foram coletados por meio de entrevistas e observação-participante das aulas ministradas ao longo de um ano letivo, cuja análise de conteúdo revelou alguns aspectos que dificultam o estabelecimento da identidade profissional docente por esses sujeitos e que podem influenciar o sucesso da sua ação didática.

\section{Introdução}

A partir de 2004, por meio do Decreto no 5.154/04 (BRASIL, 2004), o Governo Federal iniciou uma série de ações que reformularam a Educação Profissional de Nível Médio no Brasil - EPT. Dentre os diversos cursos técnicos oferecidos no âmbito da EPT, alguns fazem parte da área de Computação, como: Redes de Computadores; Computação Gráfica; Desenvolvimento e Análise de Sistemas; Suporte e Manutenção de Computadores, entre outros. A oferta de vagas na EPT é destinada a jovens egressos do ensino fundamental que desejam ter, de imediato, contato com uma determinada 
profissão. Trata-se de uma proposta de formação cidadã que prepara o jovem para o mundo do trabalho (RAMOS, 2008).

Essa formação citada por Ramos (2008) indica a necessidade de profissionais docentes habilitados para atuarem nas escolas de nível médio, de modo a atender aos objetivos da EPT. Para os cursos técnicos da área de Computação, a Licenciatura em Computação - LC - é o meio pelo qual os professores podem obter a referida habilitação para atuarem no ensino de disciplinas computacionais.

Durante o curso de LC o professor terá contato com os mais diversos conhecimentos didáticos e pedagógicos que o dotará de recursos/ferramentas próprias a sua atividade de ensino. Além disso, o contato com a profissão de professor, a partir da formação inicial (graduação), facilitará o desenvolvimento do processo de construção da identidade docente (NÓVOA, 2013).

Segundo Matos (2013), o egresso da LC estará capacitado para atuar na EPT de forma satisfatória, pois sua formação compreende, além da capacitação técnica, conhecimentos pedagógicos que irão habilitar o profissional docente para atuar na escola.

Todavia, ainda há poucos profissionais formados em cursos de Licenciatura em Computação (LC) para suprir a demanda por professores da EPT (JUNIOR, 2014). Ao passo que a EPT se expande, a formação de professores na LC não segue no mesmo ritmo (GARIGLIO E BURNIER, 2012).

A carência de professores licenciados, isto é, habilitados ao exercício da docência na educação profissional de nível médio, aliada ao entendimento de que para ser professor basta o conhecimento técnico na área de Computação, tem sido uma das principais justificativas dos gestores públicos para contratação de profissionais de Computação sem formação em curso de licenciatura para atuar em sala de aula da EPT (GARIGLIO; BURNIER, 2012).

Nesse sentido, este artigo apresenta resultados de uma pesquisa sobre o desenvolvimento da identidade de professor por profissionais sem formação pedagógica em curso de licenciatura, mas que atuam como professores da educação profissional de nível médio na rede pública estadual da Bahia.

A seguir, na Seção 2 será apresentada os principais conceitos relacionados ao tema desta pesquisa, como "identidade docente" e "mediação didática". Na Seção 3 são explicitados os passos metodológicos de coleta e análise dos dados. A Seção 4 apresenta alguns dos resultados acerca do desenvolvimento da identidade docente dos sujeitos investigados. Na Seção 5 são tecidas as considerações finais acerca dos achados da pesquisa e, por conseguinte as referências utilizadas neste artigo.

\section{Fundamentação teórica}

\subsection{Identidade docente}

Em contraponto ao entendimento de alguns gestores, para Tardif (2012) o professor é "alguém que deve conhecer sua matéria, sua disciplina e seu programa, além de possuir certos conhecimentos relativos às ciências da educação e à pedagogia e desenvolver um saber prático baseado em sua experiência cotidiana com os alunos" (p. 39). Nesse 
sentido, o autor apresenta uma lista com a pluralidade de saberes que devem fazer parte da formação profissional docente: (i) saberes da formação profissional, desenvolvidos pelas instituições de formação de professores; (ii) saberes disciplinares, desenvolvidos no âmbito das disciplinas científicas; (iii) saberes curriculares, apresentam-se concretamente sob a forma de programas escolares que os professores devem aprender a aplicar; e (iv) saberes experienciais, construídos ao longo da experiência dos sujeitos e são por eles validados (TARDIF, 2012).

Segundo Pimenta (1997), esses saberes citados por Tardif (2012) estão relacionados à construção da identidade profissional docente. Saberes que são constituídos em três dimensões: (i) da experiência, que seria aquele desenvolvido pelo professor desde quando aluno, com os seus antigos professores que marcaram aquela época, do mesmo modo, o que é produzido na prática em um processo de reflexão e troca com os pares; (ii) do conhecimento, que abrange a revisão da função da escola na mediação dos conhecimentos e as suas especialidades em um contexto contemporâneo; e (iii) dos saberes pedagógicos, aqueles que abrangem a questão do conhecimento juntamente com o saber da experiência e os conteúdos específicos e que será construído a partir das necessidades pedagógicas reais.

De acordo com Cardoso et al. (2012), os saberes curriculares (saberes referentes à prática pedagógica) são fundamentais na formação da identidade do professor, que se trata de um processo "complexo e marcado por diferentes períodos, diferentes vivências e experiências" (p. 11). Nesse sentido, a formação docente compreende os saberes desenvolvidos durante o curso destinado à formação de professores - formação inicial, o aprendizado da vida social e familiar, contempla o período enquanto estudante, as relações que se estabelecem no local de trabalho (escola) e através das relações estudantes e seus pares (professores). Além disso, essa formação está inter-relacionada à identidade docente e, portanto, devem ser analisadas em conjunto.

Segundo Nóvoa (2013), o comportamento do sujeito está aliado à sua atuação profissional na medida que sua identidade será conhecida através da forma como "vive" a profissão docente. Desse modo, o autor apresenta o que denomina de triplo A (AAA), para caracterizar o processo de construção identitária dos professores: adesão, ação e autoconsciência.

Essa abordagem apresentada pelo professor Nóvoa é claramente definida nos dizeres de Pimenta (1997): “A identidade não é um dado imutável nem externo que possa ser adquirido. É um processo de construção do sujeito historicamente situado" (p. 6).

\subsection{Mediação didática}

No entendimento de Freire (2000), a mediação didática está fundamentada no diálogo enquanto condição básica para o conhecimento. $\mathrm{O}$ ato de conhecer faz parte do processo social e o diálogo é uma forma de mediação deste processo. Por outro lado, o processo de mediação didática está relacionado à forma como o professor afeta seus alunos ao ponto de lhes provocar o desejo pelos estudos.

Para D’Ávila (2005), a mediação didática é o processo de descobrir o que os estudantes sabem e como sabem acerca de determinado conteúdo/tema, tendo o professor enquanto mediador dos saberes e tradutor. O professor torna-se um "mediador 
entre as ideias dos estudantes e os objetos de conhecimento" (D’ÁVILA, 2005, p. 236). O importante, segundo a autora, é considerar o estudante dotado de concepções culturais; além disso, a responsabilidade de mediar, com base no conhecimento prévio do sujeito, é do professor.

\section{Metodologia}

Pela necessidade de investigação em profundidade do desenvolvimento de um processo que envolve a análise do sujeito em sua relação com o ambiente educacional, optou-se pelo uso de método qualitativo de análise, conforme sugere Gatti (2013).

A decisão pela abordagem qualitativa também está relacionada às características do problema investigado (subjetividade, compreensão como base para obter o conhecimento, coleta de dados, descobertas teóricas, enfoque indutivo para análise dos dados e outros), conforme orientação de Ludke e André (2005). A coleta de dados foi realizada por meio de um estudo de caso ao longo de um ano letivo completo, com a participação de três professores de Computação (sujeitos da pesquisa) atuantes em um curso técnico em informática de um Centro Estadual de Educação Profissional - CEEP.

A amostra foi selecionada por conveniência e aceitação ao convite realizado à escola. Garantiu-se que os três sujeitos possuíam a característica fundamental única para participação na pesquisa: ser professor de Computação na EPT, atuando em sala de aula, mas sem formação pedagógica habilitadora (curso superior de licenciatura na área); de modo que o problema de pesquisa estivesse inscrito no caso investigado, justificando a opção pelo método de estudo de caso.

\subsection{Coleta de dados}

Dada a natureza da pesquisa qualitativa (avaliação em profundidade), o estudo de caso foi realizado com apenas três sujeitos, cujos dados foram coletados por meio de entrevistas e observação-participante nas aulas dos três professores (sujeitos de pesquisa) ao longo de todo o ano letivo.

A observação-participante, com o objetivo de acompanhar a atividade didática dos professores, resultou na produção de 97 relatórios de observação diária em todas as séries $\left(1^{\circ}\right.$ ao $4^{\circ}$ ano) em que o grupo de professores leciona disciplinas técnicas de Computação. A maioria das aulas/turmas observadas se concentrou no início e no final do curso, $1^{\circ}$ e $4^{\circ}$ ano, respectivamente (cf. Quadro 1).

\section{Quadro 1.Frequência de observação por ano/série}

\begin{tabular}{|c|c|}
\hline Ano/Série & Frequência \\
\hline $1^{\mathbf{o}}$ & $36 \%$ \\
\hline $2^{\mathbf{o}}$ & $10 \%$ \\
\hline $3^{\mathrm{o}}$ & $25 \%$ \\
\hline $4^{\mathbf{o}}$ & $29 \%$ \\
\hline
\end{tabular}

O formulário de relatório de investigação era composto por um cabeçalho para identificar a aula observada. Alguns campos do relatório foram: data, local, disciplina, professor (nome civil), turma, quantidade de alunos, duração da aula e nome do 
pesquisador. No corpo do relatório era escrita os acontecimentos da aula e as inferências do pesquisador.

Em cada uma das séries (quatro séries ao total), foram observadas diversas disciplinas com o objetivo de conhecer e acompanhar a atuação do professor em contextos diferentes, conforme apresentado no Quadro 2.

Quadro 2. Disciplinas observadas durante a pesqu
\begin{tabular}{|l|}
$\mid$ \\
\multicolumn{1}{|c|}{ Disciplinas } \\
\hline Arquitetura de Computadores \\
\hline Banco de Dados \\
\hline Análise e Projetos de Sistemas \\
\hline Programação Visual \\
\hline Lógica de Programação \\
\hline Informática Básica \\
\hline Segurança de Redes \\
\hline Sistema Operacional \\
\hline Redes de Computadores \\
\hline Segurança de Sistemas \\
\hline
\end{tabular}

A hora-aula no contexto investigado foi composta de 50 minutos. Todavia, o tempo contabilizado durante a observação considerou os minutos efetivamente gastos em aula; assim, o tempo em que os estudantes se deslocavam de uma sala para outra e se acomodavam foi desconsiderado. De acordo com os registros da pesquisa, foram observadas 97 aulas, que somaram aproximadamente 74 horas de efetiva observação.

Além da observação, foram realizados dois blocos de entrevistas com o grupo de professores. O primeiro bloco ocorreu no início do estudo de caso e o segundo próximo ao final do período letivo.

O objetivo do primeiro bloco de entrevistas foi coletar dados pessoais, profissionais e da formação acadêmica dos professores (perfil básico). O segundo bloco de entrevistas buscou atualizar os dados coletados na primeira entrevista, além de levantar dados sobre as concepções dos professores acerca da identidade docente, o ambiente de trabalho, a vivência na educação profissional, a mediação didática e outros elementos relevantes à teorização quanto ao desenvolvimento da identidade desses professores.

\subsection{Análise de dados}

Para analisar os dados coletados nas entrevistas e nos relatórios diários de investigação, utilizou-se a técnica de Análise de Conteúdo (BARDIN, 1979).

A Análise de Conteúdo (AC) é "um conjunto de técnicas de análise das comunicações, visando obter, por procedimentos sistemáticos e objetivos de descrição do conteúdo das mensagens, indicadores que permitam a inferência de conhecimentos relativos às condições de produção/recepção destas mensagens.” (BARDIN, 1979, p. 42), organizada em três fases: pré-análise, exploração do material e tratamento dos resultados. 
A partir da macrocategoria definida na pré-análise voltada ao objetivo da pesquisa ("desenvolvimento da identidade docente estabelecida por profissionais da Computação que atuam na docência"), definiu-se as três categorias utilizadas na análise dos dados: formação docente; identidade docente e mediação didática. Essas categorias foram extraídas dos estudos de Nóvoa (2013), Pimenta (1997), D’ÁVila (2008) e Tardif (2012), cujo objeto de investigação se aproxima do objeto desta pesquisa.

Na categoria Formação Docente investigou-se a relação da formação inicial e continuada (todo e qualquer curso que tenham participado após a conclusão do curso de graduação) com ocupação laboral no magistério. Informações acerca da formação docente (inicial e continuada - forma ou informação/não-formal) foram encontradas nos dados levantados nos dois blocos de entrevistas.

Fundamentada em Nóvoa (2013), a Formação Docente foi dividida nas seguintes subcategorias: formação inicial, formas de atualização docente e formação pedagógica continuada. Essas subcategorias estão alicerçadas na necessidade de formação inicial e continuada como professor para que seja possível ao sujeito refletir sobre sua identidade docente.

A segunda categoria analisada foi a Identidade Docente. Investigou-se como o sujeito se percebe na carreira profissional do magistério e algumas relações que se estabelecem neste processo de reconhecimento da "nova" profissão. Para tanto foram consideradas duas subcategorias: a autopercepção como professor versus profissional de mercado; e a autoidentificação e autovalorização. Essas subcategorias são oriundas de Nóvoa (2013), D’ÁVila (2008), Pimenta (1997), Pimenta e Anastasiou (2014) e Tardif (2012), quanto à percepção própria do sujeito de si e sobre si, por seus pares; a experiência laboral na docência como fator preponderante para desenvolvimento da identidade docente e os saberes adquiridos dentro/fora do ambiente escolar.

Quadro 3. Categorias e subcategorias de análise

\begin{tabular}{|l|l|l|}
\hline \multicolumn{3}{|c|}{$\begin{array}{c}\text { MACROCATEGORIA } \\
\text { Desenvolvimento da identidade docente estabelecida por profissionais da Computação que } \\
\text { atuam na docência }\end{array}$} \\
\hline FORMAÇÃO DOCENTE & IDENTIDADE DOCENTE & MEDIAÇÃO DIDÁTICA \\
\hline Formação inicial & $\begin{array}{l}\text { Autoidentificação e } \\
\text { autovalorização }\end{array}$ & $\begin{array}{l}\text { Modelos de mediação didática } \\
\text { estabelecidos }\end{array}$ \\
\hline Formas de atualização docente & $\begin{array}{l}\text { Autopercepção como professor } \\
\text { versus profissional de mercado }\end{array}$ & $\begin{array}{l}\text { Principais estratégias utilizadas } \\
\text { pelo professor em uma aula de } \\
\text { Computação }\end{array}$ \\
\hline $\begin{array}{l}\text { Formação pedagógica } \\
\text { continuada }\end{array}$ & & \\
\hline
\end{tabular}

A terceira categoria analisada foi Mediação Didática. Investigou-se a atuação em sala a partir das percepções do professor e das inferências relatadas, nos relatórios de investigação, pelo pesquisador. As subcategorias analisadas foram os modelos de mediação didática e as principais estratégias utilizadas pelo professor em aulas de Computação. A análise das subcategorias foi realizada com base nos estudos de D'ÁVila (2008) e Pimenta (1997) em seus estudos sobre os modelos de mediação didática: modelo artesanal, modelo academicista ou conteudista, modelo tecnicista ou 
instrumental e modelo reflexivo. O Quadro 3 apresenta as categorias e suas respectivas subcategorias utilizadas na pesquisa.

Com base nessas categorias, foram desenvolvidos os códigos que serviram de indicadores de cada uma das subcategorias.

Para organizar o material, especificar as subcategorias e seus códigos, visando dar suporte à análise, utilizou-se a versão livre (free) do aplicativo QDA Miner' ${ }^{1}$ (QDA).

Durante a fase de pré-análise, percebeu-se a necessidade de tratamento dos dados coletados, preparando-os para uso adequado do QDA e, consequentemente, provendo mais clareza na relação entre as informações significativas e os código criados. Para isso, foi criado um documento denominado extrato de investigação.

O extrato de investigação é um resumo da transcrição das entrevistas, contendo apenas os dados significativos acerca do perfil do professor e suas concepções, com base nas entrevistas e nos relatórios diários de investigação.

A partir do extrato de investigação, com o QDA devidamente configurado com as subcategorias e seus respectivos códigos, quantificou-se as ocorrências dos códigos nos respectivos extratos de investigação de cada sujeito participante da pesquisa. Quantificou-se também as ocorrências dos códigos (indicadores) definidos para cada uma das subcategorias. Os indicadores poderiam validar ou não as suspeitas previamente encontradas na etapa de pré-análise ou ainda indicar novas suspeitas. Essas quantificações não serão apresentadas neste texto, mas podem ser consultadas em Silva (2017).

Utilizando o extrato de investigação foi possível apurar alguns resultados que, combinados, indicam os desafios enfrentados pelos professores de Computação atuantes na EPT no estado da Bahia e as implicações diretas e indiretas no desenvolvimento da identidade de professor por esse profissional.

Considerando que a identidade docente tem seu processo estabelecido nos anos em que o sujeito começa a estudar; que a evolução desse processo perpassa pela formação inicial docente e continuada (todo e qualquer tipo de capacitação ou estudo sobre temas educacionais) durante a carreira do professor; e, além disso, é refletida pela sua atuação didática, buscou-se aprofundar esta pesquisa a fim de investigar para refletir sobre como este processo identitário acontece para/com os profissionais da Computação que atuam como professores da EPT (NÓVOA, 2013; BARRETO, 2009).

Desse modo, durante a análise dos dados, identificou-se respostas às questões relacionadas à formação inicial e continuada. Investigou-se também quais são as concepções acerca da profissão docente desse professor e como elas são refletidas na sua prática cotidiana, de modo a contribuir para a definição da sua identidade de professor de Computação (NÓVOA, 2013; BARRETO, 2009).

\section{A construção da identidade docente: alguns resultados}

Esta seção apresenta alguns resultados acerca da análise dos dados coletados durante o estudo de caso, cujo objetivo foi responder à seguinte questão norteadora: "como é

${ }^{1} \mathrm{http} / / /$ provalisresearch.com/products/qualitative-data-analysis-software/freeware/i. 
estabelecido o processo de desenvolvimento da identidade docente de profissionais da Computação que não possuem formação inicial na Licenciatura em Computação e que atuam na EPT?"

\subsection{A formação inicial dos sujeitos}

Considerando que todos os sujeitos possuem formação inicial na área de Computação e que ingressaram na docência aproveitando-se de uma oportunidade para maximizar a renda mensal, torna-se importante saber como a formação em Computação auxilia na atuação docente. Quanto à formação inicial dos participantes, é possível observar no Quadro 4.

\begin{tabular}{|c|c|c|c|c|}
\hline \multirow{2}{*}{ Professor } & Graduação & Especialização & \multicolumn{2}{|c|}{$\begin{array}{c}\text { Qempo de experiência } \\
\text { laboral }\end{array}$} \\
\cline { 4 - 5 } & Computação & Educação \\
\hline F & $\begin{array}{c}\text { Bach. Análise de } \\
\text { Sistemas }\end{array}$ & $\begin{array}{c}\text { Metodologia do Ensino } \\
\text { Superior }\end{array}$ & $\begin{array}{c}\text { Entre 1 e 2 } \\
\text { anos. }\end{array}$ & $\begin{array}{c}\text { Entre 5 e 10 } \\
\text { anos. }\end{array}$ \\
\hline J & $\begin{array}{c}\text { Bach. Análise de } \\
\text { Sistemas }\end{array}$ & $\begin{array}{c}\text { Formação Docente para } \\
\text { Bacharéis }\end{array}$ & $\begin{array}{c}\text { Entre 5 e 10 } \\
\text { anos. }\end{array}$ & $\begin{array}{c}\text { Entre 2 e 5 } \\
\text { anos. }\end{array}$ \\
\hline I & Bach. Análise de & Segurança de Redes & $\begin{array}{c}\text { Mais de 10 } \\
\text { anos. }\end{array}$ & $\begin{array}{c}\text { Entre 5 e 10 } \\
\text { anos. }\end{array}$ \\
\hline
\end{tabular}

Considerando que a formação inicial dos sujeitos não possui características que, inicialmente, os habilite a lecionar (curso de Licenciatura), investigou-se como a formação que possuem contribui na pŕatica docente, assim, os participantes foram questionados com a seguinte pergunta: "Como sua formação em Computação auxilia na sua atuação enquanto professor?”.

As respostas foram divididas em duas dimensões para melhor compreensão quanto ao conteúdo e quanto à prática. Quanto ao conteúdo, os sujeitos responderam:

\footnotetext{
"Sim. Porque ensino disciplinas específicas." Prof. F

"De forma positiva." Prof. J

"Na verdade a minha formação é um ponto positivo por conta das práticas." Prof. I
}

Os depoimentos dos professores encontram ressonância nos estudos de Veiga (2012) quanto à supervalorização do conhecimento técnico sobre o pedagógico.

Observa-se que o sujeito identificado como Prof. F é o que possui menos tempo atuando na sua área de formação, por outro lado, é o que está há mais tempo na docência e participou de um curso de Especialização em Metodologia do Ensino Superior. O Prof. J, egresso de um curso de formação docente, acompanha o entendimento dos seus pares, ratificando o entendimento do grupo que, no que diz respeito ao conteúdo, o conhecimento técnico é o foco principal da sua atuação. Outro fato que maximiza essa evidência quanto à supervalorização citada consta dos relatórios de investigação que apontam a preocupação dos sujeitos em cumprir com o programa de conteúdos das disciplinas. 
A segunda parte analisada foi a dimensão quanto à prática, a qual os participantes responderam:

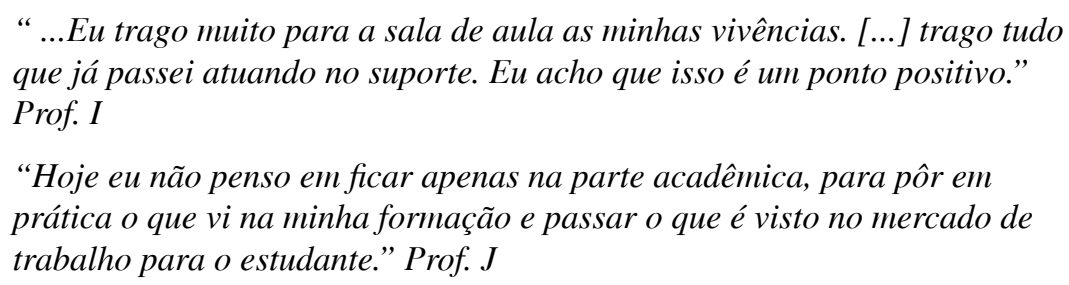

Os sujeitos participantes da pesquisa atuam diariamente com Computação fora da escola: uma parte do dia atuam no ambiente empresarial e noutra no ambiente escolar. O Prof. J concluiu um curso de 40 horas na área de Educação; o sujeito Prof. I não participou de curso semelhante, no entanto, leciona em outra instituição de ensino profissionalizante.

Os depoimentos dos professores sugerem que ambos possuem a concepção de que a sua prática em sala de aula está diretamente relacionada à sua atuação na indústria. Esses sujeitos defendem o sucesso de uma prática baseada em "contação de casos" que ocorrem no seu cotidiano laboral fora da escola.

O foco nos relatos de experiências e nas aulas práticas, com simulação de problemas reais, maximizam as suspeitas de que a formação técnica aliada à experiência laboral em Computação dão suporte às suas estratégias didáticas. Essas concepções ratificam os entendimentos de alguns autores como Veiga (2012) e Pereira (2009), quanto à valorização dada a dimensão técnica em detrimento da reflexão sobre a prática docente, também discutidas por Pimenta \& Ghedin (2002) e D’ÁVila (2013).

Essa aparente evidência apontada nos depoimentos, onde o processo de ensino é baseado no conhecimento técnico sobre o conteúdo a ser lecionado e a experiência profissional na área de Computação, fortalece o estabelecimento de um processo de formação baseado no empirismo, além de reforçar o domínio do técnico e do científico sobre o escolar (PIMENTA \& ANASTASIOU, 2014; D’ÁVILA, 2008).

Segundo Tardif (2012), essa formação empírica é importante no processo de formação docente. $\mathrm{O}$ que se discute, no entanto, é o cuidado em não mecanizar o "fazer docente" ao distanciar-se de processos pedagógicos que atuam como facilitadores do processo de ensino.

\subsection{O desenvolvimento de uma identidade do docente}

Os professores quando arguidos quanto a sua profissão atualmente, assim foram perguntados: "Qual é a sua profissão?". Tinha-se o objetivo de entender como o sujeito se identifica profissionalmente. Pimenta (1997) já indicava que a sua autoconcepção profissional implica na sua atuação enquanto profissional de mercado que agrega à docência as suas atividades laborais.

As respostas foram as seguintes:

\footnotetext{
“Eu sou Professora.”(Prof. F)

“Eu sou Professora.”(Prof. I)

“Eu sou Analista de Suporte”(Prof. J)
} 
O sujeito identificado como Prof. J está há menos tempo atuando como professor (cerca de dois anos) e, historicamente, sempre atuou no campo empresarial.

Quanto aos demais sujeitos, observa-se a autoidentificação latente em suas respostas. De acordo com os relatórios de investigação, ambos atuam há mais de cinco anos na docência e também nas suas respectivas áreas de formação inicial; todavia, refletem a profissão docente em seu cotidiano, a ponto de se identificarem enquanto professores de Computação.

Essa autoidentificação se fortalece quando os sujeitos elencam algumas características que acreditam ser fundamentais a um professor da área de Computação, como: preparar aulas, realizar aulas práticas em sala, manter boa relação com os alunos, ter comprometimento, lealdade, preocupação com o conteúdo, profissionalismo, conhecimento técnico de Computação, e conhecimento Pedagógico.

Diante das características elencadas pelos sujeitos, foi importante saber como eles se percebem em relação a elas. Assim, foram solicitados a listar até três pontos fortes que acreditavam ter e, em seguida, até três pontos que precisavam melhorar.

Quanto aos pontos fortes, listaram organização, paciência, conhecimento técnico, comprometimento, lealdade, profissionalismo, preocupação como conteúdo, espontaneidade e manter boa relação com alunos.

Por outro lado, compreendem que precisam melhorar o trato emocional com os estudantes, a prática docente, a parte afetiva (dialogar mais com os estudantes), enaltecer suas qualidades positivas, minimizando as ações negativas, melhorar a qualidade do trabalho pedagógico e buscar novas formas de conhecimento.

Segundo Nóvoa (2013), essa autoanálise dos professores reflete o grau de pertencimento à docência que o grupo já alcançou e o modo como se percebem profissionalmente, demonstrando a capacidade de agir como um profissional da docência.

Ao tempo que caracterizam o professor de Computação, refletem sobre os mesmos aspectos e buscam se perceber ou não fazendo parte desse conjunto. Com base nos relatórios de investigação, muitas dessas características, tanto pontos fortes como pontos fracos, foram registradas em diversos momentos sob situações adversas. Em alguns momentos, de acordo com os registros, a falta do apoio pedagógico (presencial) evidenciou os pontos fracos de alguns professores: estudantes desinteressados com a aula, supervalorização do conhecimento técnico, centralização do diálogo no professor, inibindo os estudantes de interagirem.

Importante observar que, mesmo tendo a concepção sobre algumas práticas que precisam melhorar, os professores não conseguem avançar por si só, alegam a necessidade de suporte pedagógico, quando afirmam que:

"Faz falta um acompanhamento pedagógico." Prof. I

“...Acho que falta um pouco de técnica.” Prof. J

Reconhecem que somente o conhecimento técnico acerca da Computação não é suficiente para sua atuação em sala de aula (TARDIF, 2012; PIMENTA \& GHEDIN, 
2002; D’ÁVILA, 2013), que sua prática não pode estar baseada somente no “empirismo” (D’ÁVILA, 2008; PIMENTA e ANASTASIOU, 2014).

\subsubsection{A importância do ambiente escolar e do projeto político pedagógico}

Considerando que os sujeitos de pesquisa, segundo eles, aproveitaram uma "oportunidade de maximizar a renda mensal" como professor e que já atuam por algum tempo na profissão docente, acredita-se que seja importante saber o nível de conhecimento que o grupo possui sobre planos daquele espaço de ensino. Assim, foram questionados: "Você tem ou teve acesso ao projeto político pedagógico do colégio?"

Todos os participantes responderam que nunca tiveram qualquer contato com nenhum documento que tratasse do projeto político pedagógico ou do planejamento da escola. De acordo com os registros, até aquele momento, por diversas razões, a escola não possuía um Projeto Político Pedagógico (PPP), mas que estava em processo de construção.

Toda escola precisa de um PPP que oficialize a organização do seu trabalho pedagógico e da sua unidade escolar. Segundo Veiga (2002, p. 1), "a escola é o lugar de concepção, realização e avaliação de seu projeto educativo, uma vez que necessita organizar seu trabalho pedagógico com base em seus alunos".

O PPP é o documento orientador de toda a comunidade escolar, de modo a alcançar os objetivos ali definidos. Em geral, trata-se de um processo democrático onde todos podem contribuir; é político por se comprometer com os interesses reais e coletivos daquela comunidade. Talvez seja possível fazer uma analogia do PPP com uma "bússola", comumente utilizada por barcos para se orientarem.

A falta de um planejamento político-pedagógico, que indique as características identitárias, traz desafios também para a construção da identidade profissional docente dos sujeitos que ali atuam.

\subsection{Processos de mediação didática}

Nesta etapa de análise, tratando especificamente da categoria Mediação Didática, investigou-se a atuação em sala a partir das percepções do professor e das inferências relatadas, nos relatórios de investigação, pelo pesquisador.

As subcategorias analisadas foram os modelos de mediação didática estabelecidos e principais estratégias utilizadas pelo professor em uma aula de Computação. A análise das subcategorias foi realizada com base nos estudos de D'ÁVila (2008) e Pimenta (1997) em seus estudos sobre os modelos de mediação didática: modelo artesanal, modelo academicista ou conteudista, modelo tecnicista ou instrumental e modelo reflexivo.

As características encontradas na prática cotidiana dos professores, com base nas inferências registradas nos relatórios de investigação, indicaram quais as características dos modelos de mediação didática estão mais presentes na prática docente, de modo a refletir a identidade de professor.

Percebeu-se os grandes desafios que precisam ser superados cotidianamente pelos professores participantes do grupo; como falta de formação inicial que os capacite 
para a docência; carência de suporte pedagógico presencial; ausência de documento formal construído pela comunidade que indique a identidade da escola; e a missão dada ao professor: ser o responsável por contribuir na formação de jovens para o mundo do trabalho por meio da Computação.

Com o objetivo de entender como esses profissionais atuam e como suas práticas refletem sua identidade profissional de professor da área de Computação, analisaram-se-se os depoimentos, amparados pelos dados constantes nos extratos de investigação. A pergunta chave a ser analisada foi: "A sua forma de ensinar, no seu entender, tem alguma relação com a forma como você aprendeu?”

Dois dos sujeitos tanto demonstraram como afirmaram que lecionam com base nos exemplos de seus antigos professores. Assim, conservavam as práticas que consideram boas e evitam aquelas que consideram ruins.

Essa forma de atuar não é uma surpresa, considerando a formação inicial do sujeito; todavia, é preciso refletir que as práticas de tempos passados já não se enquadram perfeitamente nos tempos atuais, do mesmo modo o perfil dos estudantes sofreu bastante diferenças (D’ÁVILA, 2008). Percebe-se que, embora alguns desses professores atuem há algum tempo em sala de aula e tenham participado de cursos que tangenciam a Educação, impressão sobre a prática docente está mais inclinada para uma atuação tradicional e bastante voltada ao conteúdo que lecionam, inclusive, em seus depoimentos, todos trazem como principal preocupação, o conteúdo.

A falta de suporte pedagógico fica muito evidenciada neste ponto. Em muitos momentos os professores aparentavam a necessidade de respostas para determinadas questões ocorridas em sala de aula: dificuldade de entendimento da turma, baixo índice de aproveitamento nas avaliações, planejamento deficiente das disciplinas, o foco da atuação do professor em preparar o estudante para a indústria ao invés de proporcionar uma formação crítica, reflexiva e humanística visando preparar o aluno para o mundo do trabalho de forma emancipatória, ao mesmo tempo, desenvolvendo suas habilidades de docente de Computação de forma a favorecer a construção da identidade de professor (LIMA, 2001; NÓVOA, 2013; PIMENTA, 1997).

\subsection{Síntese da análise}

De acordo com os dados encontrados no âmbito da categoria Formação Docente, os três professores possuem formação inicial em cursos superior de Bacharelado em Análise de Sistemas, além de certificados de cursos de pós-graduação lato sensu, sendo um em Segurança de Redes, outro em Metodologia do Ensino Superior e o terceiro em Formação Docente.

Além da formação docente, analisaram-se dados referentes à categoria Mediação Didática. Considerando os dados encontrados nessa categoria, é possível observar que a ausência de uma formação inicial que os habilite para lecionar, culmina por dotar o sujeito de uma certa autonomia, que suspeita-se seja bastante preocupante na medida que suas práticas são baseadas no empirismo, ou seja, uma prática de tentativa de erros e acertos, carente de um suporte pedagógico adequado.

De acordo com os dados encontrados no âmbito da categoria Identidade Docente, constata-se que os sujeitos não ingressaram na carreira do magistério como 
acontece comumente com aqueles que desejam ser professor: estudar em cursos de licenciatura. Assim, um dos passos iniciais para o desenvolvimento da identidade de professor (NÓVOA, 2013), não foi cumprido, pois, como já informado antes, a formação inicial dos sujeitos não contemplou aspectos didáticos-pedagógicos. Neste sentido, se mostrou importante investigar como aconteceu o ingresso na carreira do magistério. Ao serem perguntados sobre "Como você se tornou-professor?", responderam:

\footnotetext{
“Por acaso. ... surgiu a oportunidade de vir trabalhar...” (Prof. F)

“A partir de uma oportunidade que surgiu, por acaso....” (Prof. J)

"Comecei na docência meio que por acaso, eu estava trabalhando em uma empresa como analista de suporte e surgiu a oportunidade.” (Prof. I)
}

Os depoimentos dos sujeitos parecem revelar que inicialmente não havia o desejo de lecionar. Os sujeitos ingressaram na docência aproveitando-se da oportunidade de melhorar sua renda mensal por meio de um segundo vínculo laboral com o magistério. Essa suspeita surgiu no fato de um dos sujeitos trabalhar apenas como professor, mas sua vida profissional ter se iniciado como analista de sistemas, atuando na indústria de software; outro sujeito está há mais de cinco anos trabalhando como professor, trabalha em duas unidades de ensino distintas e atua como profissional liberal nas horas vagas; e o terceiro sujeito, atua como professor há pouco mais de dois anos, mas também exerce a atividade de Analista de Suporte.

Suas práticas cotidianas corroboram com as reflexões de Nóvoa (2013) quanto aos símbolos observados no sujeito, características claras de um profissional da docência. Ainda que não possuam formação inicial na Educação (curso de licenciatura), atuam profissionalmente como professores, não mais com o simples desejo de maximizar a renda mensal, mas com o desejo de refletir sobre a profissão docente e aprofundar o seu aprendizado, a fim de melhorar sua prática cotidiana, conforme demonstrado nas observação e entrevistas.

O processo de construção da identidade docente, no entanto, não depende apenas da formação inicial do sujeito. Conforme entendimento de Pimenta (1997), a identidade docente é parte de um processo de construção do sujeito historicamente situado. Assim, requer aprofundamento nos dados coletados para investigar como a atuação dos professores participantes, a sua relação com seus colegas professores, com o local de trabalho, com seus gestores e suas concepções sobre o estabelecimento do processo identitário.

Para determinar o alcance das possíveis respostas, retorna-se à questão norteadora: "como é estabelecido o processo de desenvolvimento da identidade docente de profissionais da Computação que não possuem formação inicial na Licenciatura em Computação e que atuam na EPT?". Embora os sujeitos participantes não possuam formação inicial (graduação) em curso de Licenciatura, apurou-se que eles sentiram a necessidade de buscar conhecimentos pedagógicos. Dois sujeitos concluíram cursos de pós-graduação lato sensu cujo conteúdo, conforme informaram, tangencia a Educação e o fizeram de livre vontade.

Quanto à atuação dos professores, apurou-se que suas práticas são baseadas nas tentativas de erros e acertos, focalizadas principalmente no conteúdo das disciplinas de 
Computação, de modo a inviabilizar que o estudante possa se apropriar de forma autônoma e reflexiva acerca do assunto estudado, para enfim produzir novos conhecimentos.

Refletem sobre suas práticas "empíricas" e compreendem a necessidade de mudanças, reconhecem que precisam de suporte pedagógico e orientações basilares acerca dos objetivos que orientam a escola onde atuam.

A carência de suporte pedagógico, aliada à falta de documentos formais que reflitam a identidade da escola, culminam por prejudicar o desenvolvimento da identidade docente dos professores de computação sem formação inicial na Licenciatura atuantes na EPT.

\section{Considerações Finais}

Este artigo apresentou alguns resultados de uma investigação sobre o processo de desenvolvimento da identidade docente por professores de Computação sem formação pedagógica em nível de Licenciatura, atuantes na Educação Profissional de Nível Médio em uma escola pública do estado da Bahia.

Apurou-se que os desafios para desenvolvimento da identidade de professor por esses profissionais minimizam as chances de sucesso didático-pedagógico, por causa de diversos fatores (causais) relacionados ao ambiente, às concepções de educação e à ausência de formação inicial no campo da Licenciatura. Esses fatores se refletem (consequência) nos modelos de mediação didática adotados por eles.

A falta de formação inicial que capacite o profissional a lecionar se mostra como um desafio a ser superado. Neste sentido, é possível que a Licenciatura em Computação contribua de forma significativa por formar profissionais qualificados e habilitados para o exercício do magistério. Além disso, é preciso mais estudos acerca do tema, de modo a alargar o campo epistemológico sobre a formação de professores de Computação, em um diálogo constante com outras áreas do conhecimento, estabelecendo a Educação em Computação como de fato um campo de pesquisa (MATOS \& SILVA, 2012).

Outra desafio a ser superado é a falta da identidade na escola. Uma escola, conforme afirma Veiga (2002), necessita de um planejamento formal, mas que não seja apenas um arranjo para cumprir as determinações dos órgãos superiores, mas um documento construído democraticamente por toda comunidade atuante de forma a refletir sua identidade e, assim, proporcionar aos seus professores o desenvolvimento de suas próprias identidades profissionais através da vivência, segundo as orientações definidas para o coletivo escolar.

Como trabalho futuro, sugere-se ampliar a investigação acerca do desenvolvimento da identidade docente em Computação, a partir das concepções filosóficas, sociais e políticas que permeiam o ambiente escolar e os professores que atuam na Educação em Computação. 


\section{Referências}

Bardin L. (1979). Análise de conteúdo. Lisboa: Edições 70.

Barreto, M. A. M. (2009). Ensinando a ensinar - a importância do modelo na formação de professores. Revista Práxis, v. 1, n. 1. Disponível em: https://goo.gl/aXRvb9. Acessado em : 21/04/2018.

Brasil (2004). Decreto $n^{\circ}$ 5154, de 23 de julho de 2004. Disponível em: https://goo.gl/YXTDdk. Acessado em: 16/04/2018.

Cardoso, A. A.; Pino, M. D.; Dorneles, C. (2012). Os saberes profissionais dos professores na perspectiva de Tardif e Gauthier: contribuições para o campo de pesquisa sobre os saberes docentes no Brasil. In: Anais da IX ANPED Sul, Seminário de Pesquisa em Educação da Região Sul. Disponível em: https://goo.gl/iPQfe1. Acessado em: 17/04/2018.

D’ÁVila, C. (2005). A mediação didática na história das pedagogias brasileiras. Revista FAEEBA, v. 14, n. 24, p. 217-238.

. (2008). Formação docente na contemporaneidade: limites e desafios. Revista FAEEBA, v. 17, n. 30, p. 33-41.

. (2013). Decifra-me ou te devorarei: o que pode o professor frente ao livro didático?. Salvador: Eduneb.

Freire, P. (2000). Pedagogia do oprimido. 29ª ed. São Paulo, SP: Paz e Terra.

Gariglio, J. A.; Burnier, S. (2012). Saberes da docência na Educação Profissional e Tecnológica: um estudo sobre o olhar dos professores. Educação em Revista, Belo Horizonte, v. 28, n. 01, p. 211-236.

Gatti, B. A. (2013). Implicações e perspectivas da pesquisa educacional no Brasil contemporâneo. Cadernos de Pesquisa, Fundação Carlos Chagas, n. 113, p. 65-81.

Junior, E. V. B.;Lopes, K. M.; Balduino, A. R.;de Sousa, J. M. (2014). O desafio da prática docente sem a formação de licenciatura em computação. In: Anais da, $V$ Jornada de Iniciação Científica e Extensão (V JICE), Tocantins. Disponível em: https://goo.gl/xBPWXS. s/p. Acessado em: 20/03/2018.

Lima, A. A. B. (2001). Educação Profissional para quê?: construindo a formação dos trabalhadores para além do falso consenso. Salvador: UFBA/FACED.

Ludke, M.; André, M. E. D. A. (2005). Pesquisa em educação: abordagens qualitativas. São Paulo, SP: E.P.U.

Matos, E.; Silva, G. (2012). Currículo de licenciatura em computação: uma reflexão sobre perfil de formação à luz dos referenciais curriculares da SBC. In: Anais do XXXII Congresso da Sociedade Brasileira de Computação. XX Workshop sobre Educação em Computação (WEI). s/p.

Matos, E. (2013). Identidade profissional docente e o papel da interdisciplinaridade no currículo de licenciatura em computação. Revista Espaço Acadêmico, v. 13, n. 148, p. 26-34. 
Moura, D. H (2015). A formação de docentes para a educação profissional e tecnológica. Revista Brasileira da Educação Profissional e Tecnológica, v. 1, n. 1, p. 23-38.

Nóvoa, A. (Org.) (2013). Vidas de Professores. 11ª ed. Lisboa: Porto Editora.

Pereira, L. A. C. (2009). A formação de professores e a capacitação de trabalhadores da educação profissional e tecnológica. Portal MEC, v. 3. p. 1-9. Disponível em: https://goo.gl/4nNYpx. p. 1-6. Acessado em: 20/03/2018.

Pimenta, S. G. (1997). Formação de professores - saberes da docência e identidade do professor. Nuances, v. 3, p. 5-14.

Pimenta, S. G..; Anastasiou, L. G. C. (2014). Docência no Ensino Superior. $3^{\mathrm{a}}$ ed. São Paulo: Cortez.

Pimenta, S. G.; Ghedin. E. (2002). Professor reflexivo no Brasil: gênese e crítica de um conceito. São Paulo: Cortez.

Ramos, M. N. (2008). Concepção do ensino médio integrado. In: Seminário sobre o ensino médio. RN: Secretaria Estadual de Educação - Natal Disponível em: https://goo.gl/1ne8TW. Acesso em: 09/05/2018.

Silva, R. S. (2017). Formação docente e as práticas do professor de computação na educação profissional. Dissertação (Mestrado em Ciência da Computação), Universidade Federal da Bahia, Salvador/BA.

Tardif, M. (2012). Saberes Docentes e Formação Profissional. Petrópolis, RJ: Vozes.

Veiga, I. P. A. (2012). Didática: uma retrospectiva histórica. In: VEIGA, I. P. A. (Org.). Repensando a Didática. $29^{\mathrm{a}}$ ed. Campinas, SP: Papirus.

(2002). Projeto Político Pedagógico da Escola: uma construção possível. 14a ed. Campinas, SP: Papirus. 